\title{
HOLISTIC HERITAGE BUILDING INFORMATION MODELLING (HHBIM): FROM NODES TO HUB NETWORKING, VOCABULARIES AND REPOSITORIES
}

\author{
R. Brumana ${ }^{\text {a }}$, M. Ioannides ${ }^{\mathrm{b}}$, M. Previtali ${ }^{\text {a }}{ }^{*}$ \\ ${ }^{\text {a }}$ Politecnico di Milano, Department of Department of Architecture, Built Environment and Construction Engineering, DABC LAB \\ GIcarus, Via Ponzio 31, 20133 - (raffaella.brumana, mattia.previtali)@ polimi.it; \\ ${ }^{\mathrm{b}}$ CUT, Cyprus University of Technology, Department of Electrical Engineering, Computer Engineering and Informatics, UNESCO \\ Chair on Digital Cultural Heritage, Digital Heritage Research Laboratory, Arch. Kyprianou 31, CY 3036 Limassol, CYPRUS, - \\ (marinos.ioannides@cut.ac.cy);
}

KEY WORDS: Holistic HBIM, Heritage Building Information Modelling, eXtended vocabularies, construction systems

\begin{abstract}
:
HBIM (Heritage Building Information Modelling) can be nowadays considered as part of the digitization process of Cultural Heritage, with the particular characteristics that being born to manage Models and Data within a unique environment they can be inherited to adopt a synergic approach to the cultural Heritage 'as a whole system'. To this aim they need to overcome gaps and barriers undertaking an holistic approach in many directions. The paper intends to introduce an overview on the meaning of Holistic Heritage Information Building. The attribute holistic is here used with the meaning to empower instruments and methods capable to interconnect single HBIM nodes within networks where to find the information collected in a cross sectorial space: vocabularies, libraries of object and semantics, derived from such 'Informative Models' - with the support of Virtual Hub technologies - can boost nodes-networking empowering the capabilities of BIM Informative Modelling together with web accessible Geographic Informative System. Such richness once interconnected can be accessed from space-temporal queries, semantic searches, and harvested with other networks in order to enhance the cross correlation of the information and allowing the sharing of different case studies and HBIM within a space-temporal framework. This will allow the comparison of masonry texture, history of material finishing and skilled workers across space and time. HHBIM HUBS will be a gate toward the eXtended Reality potentials attracting and distributing data coming from different sources.
\end{abstract}

\section{INTRODUCTION}

Nowadays the digitization process complains data and systems where to relate the richness of information. HBIM correlates 3D models - describing the geometry of heritage architectural objects and their elements (i.e. walls, covering systems, vaults, decorations) - to different pieces of information (materials, construction techniques, physical properties, decay, dating, historical data, volume data, archive data, documents). The Strategic Research agenda for JPI-CH highlighted the large domain of the Cultural Heritage and consequently of its digitization $^{1}$ strengthening the attention on the inclusive process of tangible and intangible information. Given the complex domain of the $\mathrm{CH}$, HBIM needs to be interpreted toward an holistic framework this paper intends to introduce. Heritage BIM (HBIM) can be considered a powerful instrument of attracting different data with different formats and contents. They represent an extraordinary opportunity to entail the

\footnotetext{
1 "Cultural heritage exists in tangible, intangible and digital forms. Tangible heritage includes artefacts (for example, objects, paintings, archaeological finds etc), buildings, structures, landscapes, cities, and towns including industrial, underwater and archaeological sites. It includes their location, relationship to the natural environment and the materials from which all these are made, from prehistoric rock to cutting edge plastics and electronic products. Intangible heritage includes the practices, representations, expressions, memories, knowledge and skills that communities, groups and individuals construct, use and transmit from generation to generation. Digital heritage includes texts, databases, still and moving images, audio, graphics, software and web pages. Some of this digital heritage is created from the scanning or converting of physical objects that already exist and some is created digitally, or 'born digital'. Whatever its genesis, it needs constant maintenance and management to be retained."
}

richness of the information collected during researches and interventions, preservation and conservation activities within a whole system. Indeed, in the last years several projects focused on cultural heritage digitization: surveying, modelling activities, diagnostic analysis and historic data collection of architectural heritage. Such actions have been mainly carried out to support the preservation process. Many other precious data are further collected during the restoration and construction site enriching the knowledge on the heritage. Unfortunately, many of them are left abandoned after the research or after the intervention, in a latent status, without any connection with the long life cycle of the historic architectures or connection to the citizen dissemination. HBIM, once delivered, is at the crossroads of reentering into the phase of forgetfulness: but it could play the critical role of a precious witness into the future being, transferring the richness of such virtual informed model to the people, tourists, citizens and future co-actors involved in the maintenance management. Heritage Building Information Modelling (HBIM) represent systems based on Common Data Environment where the different actors can share data and exploit their BIM BASED activities, accessing to the different data growing with the BIM logic (BIM-BEM, BIM-FEA, Energy Efficiency, CoSIM, LLCCM). HBIM nodes need to be correlated once to each other, strengthening the relationships among all the information gathered (tangible and intangible). This requires to gain an 'holistic' dimension outside the HBIM itself, relating all the HBIM nodes to the environment to climate change challenges and hazard events in order to better support the preservation policies. Also, a holistic documentation of monuments and integration of all data in BIM data base structures, needs to take into account not only tangible, but also intangible stories, memories and knowledge about buildings and sites needs to be entailed within HHBIM. Along with the 
development of metadata, semantic rules and corresponding HBIM ontologies, using standard, as CIDOC/CRM, for the archiving and catalogues data management directly connected to the HBIM (Kuo et al., 2018). To reverse loss of information the HBIM nodes require to be connected each other creating common holistic hubs exploiting the impact (Figure 1).

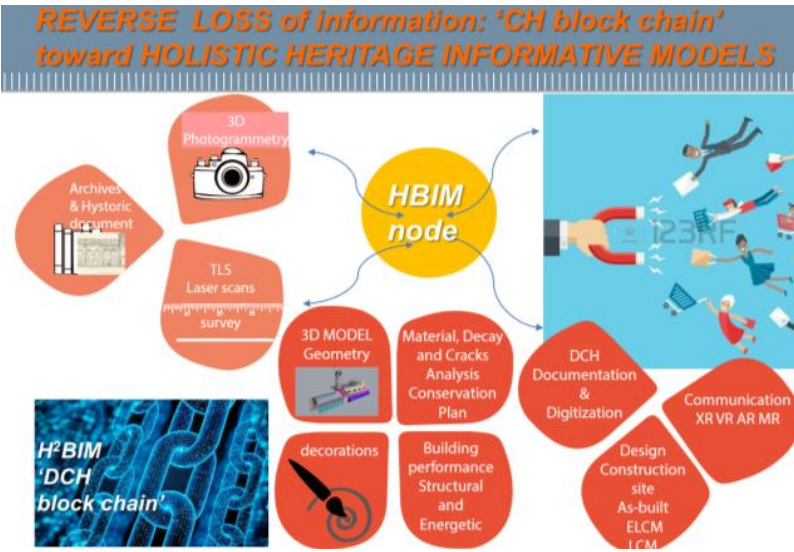

Figure 1. Holistic HBIM challenges: to reverse loss of information acquired during historical research, design and intervention

\section{HOLISTIC HERITAGE INFORMATION MODELLING (HHBIM)}

\subsection{BIM adoption: the EUPPD24/2014 directive. Gaps and barriers, time-cost effectiveness.}

EUPPD 24/2014: the EU Directive on Public Procurement asked the 28 EU countries to adopt 'building informative modelling' by February 2016 in order to support the whole LCM (Life Cycle Management). Many analyses foresees, in fact, to save from around 5\% to $15 \%$ of the overall investment by adopting mature BIM. The Italian Public Procurement Legislation (D.Lgs 50/2016, L. 21/06/2017 n.96, Nuovo Codice degli Appalti pubblici) has been aligned with the EUPPD 24/2014 adopting rewarding scores progressively decreasing in relation to the PP amount of tenders in order to give time to the professionals and companies to building capacity in the BIM adoption.

The adoption of the BIM represents a challenging issue, especially during difficult economic periods like this one, since it represents a cost and a difficult change of habits in the design and management phase, moving from the traditional 2D representations to the full 3D BIM enabled management.

The maximum of the investment is at the starting phase, while the earn is expected during the construction site management with a reduction of the cost changes, in the case of HBIM due to unknown aspects and during the management phase along the Life Cycle Management (Figure 2). In order to tackle the HBIM adoption it is necessary to undertake different actions devoted to tackle two of the main issues: improve the time-cost effectiveness and diminishing the gaps nowadays present. On one side it is mandatory to introduce protocols and best practices, customized routines, and others actions, in order to diminish the starting cost, that in the case of the HBIM is bigger than for new building. On the other side it is mandatory to span the cost spreading the use after the HBIM generation toward an holistic vision capable to entail different aspects and to share all the data collected by different actors, including citizens.

Born as management system to support real estate maintenance across the time (as the US navy building), they are mainly adopted by professionals to follow the design phases, the construction site, till to the as-built and Long Life Cycle Cost Management (LLCCM) after the intervention.

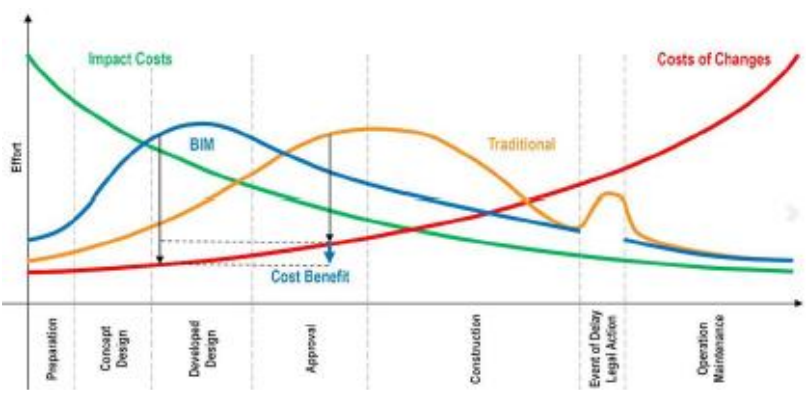

Figure 2. BIM vs Traditional CAD Planning - source_P. Mac Leany HOK and Dr T. Liebich, AEC3 Deutschland GmbH, 2013

\subsection{Inclusive HBIM}

Conservation of built heritage is progressively linked to the maintenance of monuments and defining preventive conservation as a real necessity in everyday practice. In this view, it is necessary to have an instrument that allows for the collection, analysis, comparison, archiving, sharing and management of all the data available concerning the geometry, topology, materials, structure and state of conservation of each historical buildings. Such data sets include not only the products of surveys, drawings, thematic, intangible and historical contents, but also information about maintenance or restoration activities and many other relevant forms of information (such as sketches, images).

BIM can be defined as an intelligent 3D model-based process that gives architects, civil, electrical, environmental, chemical engineers, construction professionals and others the insight and tools to more efficiently plan, analyse, design, construct and manage buildings. Traditionally introduced and mainly adopted for new building the BIM methodology is characterized by a linear process progressively conceived to enrich the Level of Geometric (LOG) and Information (LOI) of substantially 'simple' objects - following the building construction from the conceptual phase to the executive design phase till to their Long-Life Cycle Management across different Level of Development (LOD).

This traditional design logic requires to be completely reviewed, in order to take into account the use of BIM in the Cultural Heritage domain field (Brumana et al., 2018a). In this unique area of research and development, the buildings are not designed but reconstructed from billions of scanned point clouds (digitization and 2D/3D reconstruction modelling) by considering the specificity and the unicity of each object component belonging to a monument or archaeological site, starting from the unicity of the morphological and geometric characteristics. Under the modelling issue, innovative Generative Modelling processing coming from the point cloud extraction of geometric primitives (Banfi, 2017) have been introduced to match the complexity and unicity of the $\mathrm{CH}$ : to this aim the adoption of different Grade of Generation have been introduced, with many potential in decoding complex shapes as in the case of apparently similar vaulted objects (Brumana et al., 2018a) or to support the design conservation plan of post damaged architectural heritage, as in the case of an earthquake (Brumana et al., 2018b).

The introduction of the BIM concept in Cultural Heritage requires therefore a particular attention to switch from pure 2D/3D models to HBIM in order to support preventive conservation, information sharing and knowledge dissemination 
of heritage, for professionals, public institutions and experts involved in the decision-making process (Della Torre, 2016). Holistic HBIM has thus to be intended as a 'gear' to keep information and models connected across space and time, at the different scales, enabling co-working by multidisciplinary actors, with different expertise, in order to collect all the information coming from the analytical phases to satisfy the need to maximise knowledge in support of preservation aims (Figure 3). Such information span from the architectural scale, including the geometric surveying, the analysis of materials and decay, historical researches and documentations - including the provenience of materials, or intangible oral information about the construction techniques adopted in the past by the skilled workers across Europe and regions -, right through to the geographic information richness nowadays recognized as indispensable to gain an organic awareness of all the factors that can represents pressures to be mitigated by preservation actions. Therefore, HHBIM represents a challenging methodology adapted to a dynamic system - for generating enriched data about the uniqueness of the architectural heritage to enhance knowledge, preservation and planned maintenance across Long Life Cycle Management and Monitoring HBIM policy (Della Torre, 2017).

\section{BOOSTING INTEROPERABILITY AMONG ACTORS \\ HBIM to manage the PRESERVATION PLAN\&LCM}

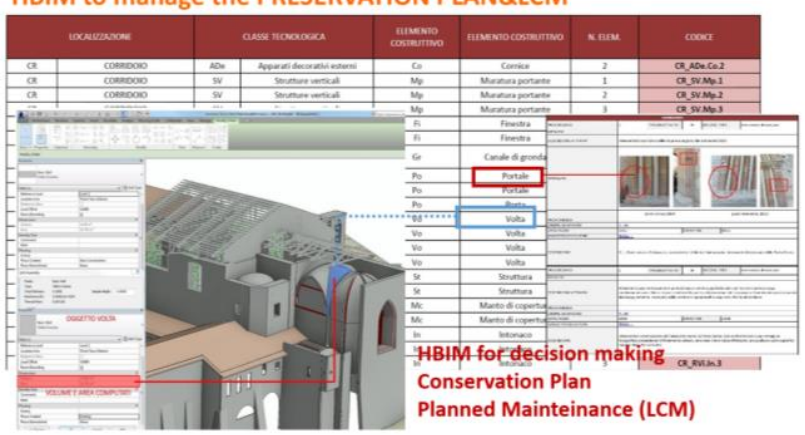

Figure 3. HBIM to support the Conservation Plan and Planned Maintenance across the Life Cycle Management (LCM)

HHBIM must include the addition of Geographical Information data (GIS) for environmental monitoring and protection reasons. This geographic information spans from the natural hazard information, managed by the integration of satellite data (e.g. Copernicus programme) boosting the contribution of the Earth Observation to the knowledge of the on course phenomena in damaged regions or risk areas (Cuca, 2017), together with ground based information, documenting and monitoring the geological and hydrogeological risk maps, earthquake risk areas, raining indexes, rainfall-flooding-desertification areas under climate change pressures. Such data will progressively include the growing availability of real-time Open Data, such temperature, raining parameters and sea level rises, to cite just some of them. HHBIM is expected to create capacity building to manage and monitor process, including real time sensor data acquisition in the different scenarios within an integrated HHBIM-GIS environment.

\section{HBIM: FROM PUNTUAL NODES TO NETWORKS: GEODB-HBIM HUB}

The HBIM represents a punctual analysis concentrated on different subjects (architectural heritage, archaeological site and others) for which it is developed, each one with its specificity. Once generated each HBIM represents a node of information. In order to avoid the risk to loose such richness and knowledge, leaving the result in a drawer once closed the study, the dissemination effort or the intervention, we need as a further step to give to such 'structured' data source the possibility to be circulated among others HBIM, generating network of knowledge across space and time. The paper tries to identify a possible workflow, in this direction (Figure 4).

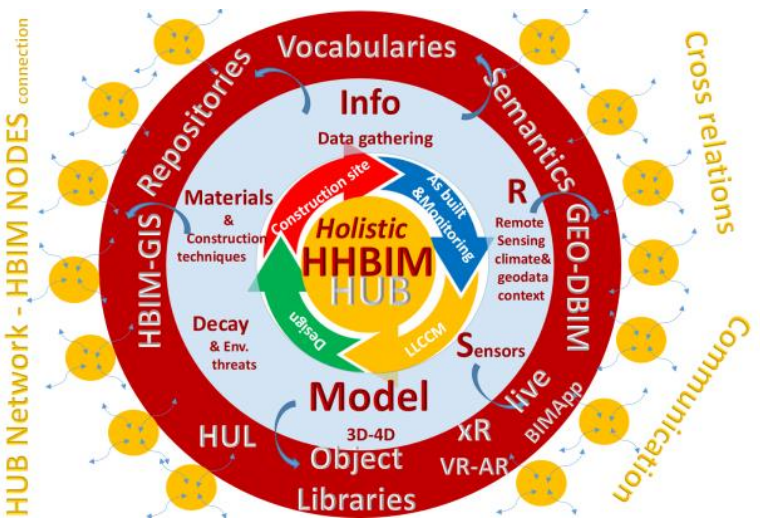

Figure 4. Holistic HBIM Hub workflow scheme: hub network connecting the HBIM nodes

The availability of growing HBIM will increase the opportunity to access to all this nodes in a cross sectoral way in order to correlate all the nodes and the information contained. Experimentations starting designing cloud based platform boosting the metadata and semantic based search virtual hub (Mazzetti, 2015) are on course. Such hubs allows to discovery and access different open data through semantic, space and temporal queries (Previtali, 2017).

A 3D GeoDB Hub has been set up to populate different sourced 3D models and HBIM of Architectural Heritage, palaces, churches, art-facts, archaeological site, with the related information at a geographic scale, with the possibility to access different Open Data, (Brumana et al., 2018c): each HBIM with its specificity and uniqueness, can progressively find in the platform a common space where to correlate across the time and the spaces the different information related to the HBIM: as in the case of the materials, construction techniques, and all the properties related to the models, climate data, geographic data and so on.

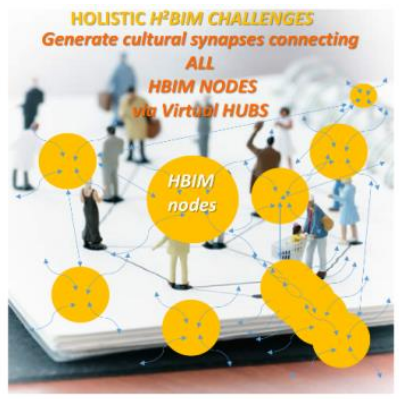

Figure 5. Holistic HBIM networking to generate cultural synapses

The result is a virtual space where it is possible to 'connect' information, finding the different skilled workers families, the employed art crafts, the oral traditions, the traces of their knowledge developed, tangible and intangible information of the heritage, allowing people, experts and non experts, to give back unexpected picture of the complex richness of the construction techniques across the world and allowing the discovery of relationships among territories, and multiplicity of 
identities mixed one to the other. Different construction techniques, permanencies and mutations can be returned back by an Holistic approach to the HBIM (HHBIM) connection. Holistic HBIM networking is aimed to generating cultural synapse among all the actors through the HBIM nodes connections (Figure 5).

\section{THE ADDED VALUE OF VOCABULARIES IN THE CREATION OF A COMMON SHARED KNOWLEDGE}

To start working in this direction, it is becoming mandatory to strengthen common shared languages coming from the richness of the 'Information' derived from the HBIM, in order to allow a cross relation among punctual HBIMs. A bottom up process where the richness of each HBIM source can feed common shared vocabularies.

Vocabularies can represent a common switch among the Heritage BIM description and the capability to search across different HBIM within HUB networking. Holistic approach means also the possibility to boost an organic vision to the whole aspects involved by the HBIM, that means geometry, information, tangible and intangible values, within a networking.

The "Encyclopédie ou dictionnaire raisonné des sciences, des arts et des meétiers" (Diderot and Le Rond D’Alambert, 1753) contributed to highlight the value of vocabularies in the creation of a common shared knowledge. The value of architectural vocabularies connected to the construction techniques, in the history, have been progressively underlined (Pérouse de Monclos, 1972), rediscovering the ancient treats and manuals (i.e. De L'Orme, 1561; Rondelet, 1802) contributing to rediscover the regional traditions in the use of materials and construction techniques, as in the case of the French repertoires of the construction systems.

Vocabularies and gazetteers have been nowadays implemented for many purposes in presence of massive data sets (as the Art Catalogue collection of Museums, or of Archives).

The availability of HBIM collecting all the information on the materials and masonry arrangement can progressively implement ad hoc updatable vocabularies that could be correlated to each space temporal HBIM ID-object and vice versa.

\subsection{Getty Vocabulary}

The Getty Vocabulary represents nowadays the most outstanding huge effort at the world scale to release validated shared vocabularies, constantly growing under the leverage of multiple projects and initiatives, demonstrating the 'in-finite', in the sense of never endless working, adopting the most advanced ICT standards of collecting and publishing such data. The ID Cultural Heritage Object Code has been introduced by the Getty Vocabulary, underlining the unicity of each object and at the same time the necessity to connect all the objects progressively thanks to semantics and content definition.

The lesson learnt and the added value of Getty vocabulary can be usefully nowadays integrated to the 'I' of the HBIM (Heritage Building Information Modelling), enriching the architectural vocabularies.

Space-time semantic based search system, as the modern HUBs, allows through the vocabulary to preserve the vocabulary tradition, innovating them thanks to unexpected relations when related to the 3D HBIM models and to their granular information.
The tradition of the historical treats and manuals can be renovated and linked to the HBIM-vocabularies, creating eXtended Vocabularies intended as an umbrella rediscovering the ancient tradition of the vocabularies, and reinterpreted under the modern HBIM tools. They can be intended as a modern instrument to empower the comprehension and diffusion of knowledge in the case of architectural heritage. This creates a transversal common knowledge with the richness of bottom-up process that collects the information on materials or construction system through the HBIM.

\subsection{The case of vaulted systems}

The increasing importance of informative models (i.e. HBIM) have completely redesigned the role of $3 \mathrm{D}$ models. This paper intends to boost the holistic meaning toward the capacity to use the available metadata schema (i.e. Archives and Maps data collections, Object collections, Geographic Open Data, Data Base) and at the same time to entail the metadata structure for 3D informative models.

Such holistic approach has been applied to the case of vaulted systems. Vaulted systems represented in the past a common architectural covering that have been widespread diffused across centuries and spaces as a result of territorial traditions diffused across European regions, North Europe, Middle East regions and Mediterranean regions till to Latin American countries just to cite some cases. Thanks to the activities of skilled worker families (as in the case of the famous 'Magistri Comacini' from the Como Lake during the Middle Age, and many others s families working in Europe as well during the centuries), it has been progressively documented the adoption of a multiplicity of solutions that overcome the common typological subdivision. Similar construction techniques, arrangements, centrings construction can be found across the regions with at the same time an unexpected variety of solutions. Unfortunately a cross-sectorial knowledge of such knowledge is nowadays largely absent, sometimes just documented and jeopardized at a local dimension without any correlation at a global accessible dimension where to relate all the gathered information.

As an example, during the last 15 years authors had the opportunity to study different vault cases, surveying and modelling their intrados and extrados to investigate the geometric shape, through the photogrammetric surveying, laser scans and thermal image data acquisition, to analyse the masonry arrangements, and collecting data from the private and public archives on the acquisition of the palaces and transformation occurred during the centuries. We highlighted the richness of the construction techniques and of the decorations. Investigating the 3D geometric modelling we found out many mixed constructive solutions among the classification of the vault 'typologies', contributing to evidence subtypologies groups, with cases of morphology tuned toward multiple-generative models: sail vaults tuning toward the groined shape (Oreni, 2013), domes tuning toward cloister vaults, mixed arched/vaulted structures adopting thin shells, cloister vaults tuned to 'trompe' switches on the corners (Brumana et al., 2018b). In the meanwhile many other authors are studying vaulted systems under different point of views across the world rediscovering different construction techniques (Holzer, 2013, Piccoli,1999, Napolitano, 2017). But at the same time we lost during the years a lot of drawing and models carried on during the different researches, limiting the possibility to derive transversal connections and new knowledge from the co-relation among the different studies.

In particular in these case studies, it has been generated many HBIM (Heritage Building Information Models) vault samples 
relating the $3 \mathrm{D}$ model to the information collected, containing the description of the vaults, the structural components their arrangements, the sub-typologies encountered, and decorative layers, the construction periods, the geographic position of the palaces, churches, and other building or infrastructures they belongs to (Figure 6): once modelled the HBIM vault Model object ('M') integrating the 3D texture through the IRT thermal analysis, to each vault component it has been related different information ('I'): as the Typology (i.e. Vault, Cloister), the Construction Technology (degenerative Cloister to Trompe), the arrangement description ('in folio' texture for the thin shell or soldier laid for the reinforced arches), the texturing mode, dimensions of the brick block, a textual description, dates, and others data collected during the research.

On the base of the different HBIM generated, all such information and properties have been used to create an external DB and a vocabulary creating a common shared vocabulary built on the specificity of the object encountered. A Vault vocabulary has been implemented on the base of the HBIM generated. The process is not automatic, but for the future it would be worth to update the different vocabularies. As this matter of fact together with a group of researcher and colleagues last year we started working to the construction of an updatable Geographic Data Base Hub (GEODB HUB) with linked 3D models coming from detailed surveying, from Scan-to-BIM processes, HBIM (Heritage Building Information Models), or from other modellers, together with 3D orthophotos of the intrados and extrados coming from the photogrammetric processes. The richness of each vault system gives back an 'unicum', described by a rich terminology and vocabulary in the Information related to the vault Model ('I' of HBIM). Terms like:

- 'stereotomy' tradition inherited by the spatial stone cutting tradition coming from Egyptians and other societies, till to the middle ages traditions applied to the arches and vaulted cathedrals, till to the baroque periods, have been applied also to the masonry brick tradition (Piccoli, 1999);

- 'frenelli' (the masonry walls giving stability to the vaults at the extrados level springing from the vaults);

- 'in folio' arrangements characterizing thin shells vaults are highlighted in the world by different researches in different areas (Brumana et al., 2018c);

- 'trompe' (switch), complex geometric surfaces as junction on the corners of vaulted elements investigated by Guarino

Guarino in the XVII and realized in many architectures across the centuries (Guarino Guarini, 1737).

are typically discovered in common aristocratic palaces, as in the Magio Palace case study (A.G.Landi, 2016, Brumana et al., $2018 \mathrm{~b}$ ). The HBIM collects many of this terms that introduce a multi-variety of creative solutions adopted by the construction typology.

A GEODB has been developed using Discovery and Access of Brokering System standard adopted for Geographic Open Data; it is based on semantic search, geographic or temporal search. Different queries can be performed on the DB or on the GEODB. An open access geospatial Data Base based on a Virtual Hub technology with the possibility to link the punctual informative models (HBIM). Starting from an application (GEOPAN APP) implemented on a Virtual Hub has been developed to support the redistribution of Geographic Open Data. The Hub allows to carry on semantic search, and perform different queries (Figure 7). From a technical perspective, GeoPan Atl@s is built on the basis of the HTML/CSS/JS structure. This way GeoPan Atl@s can be accessed by all browsers supporting HTML5 (e.g., Safari iOS, Google Chrome, Firefox, Internet Explorer, Opera) both from desktop and mobile (e.g. tablets and smartphones).

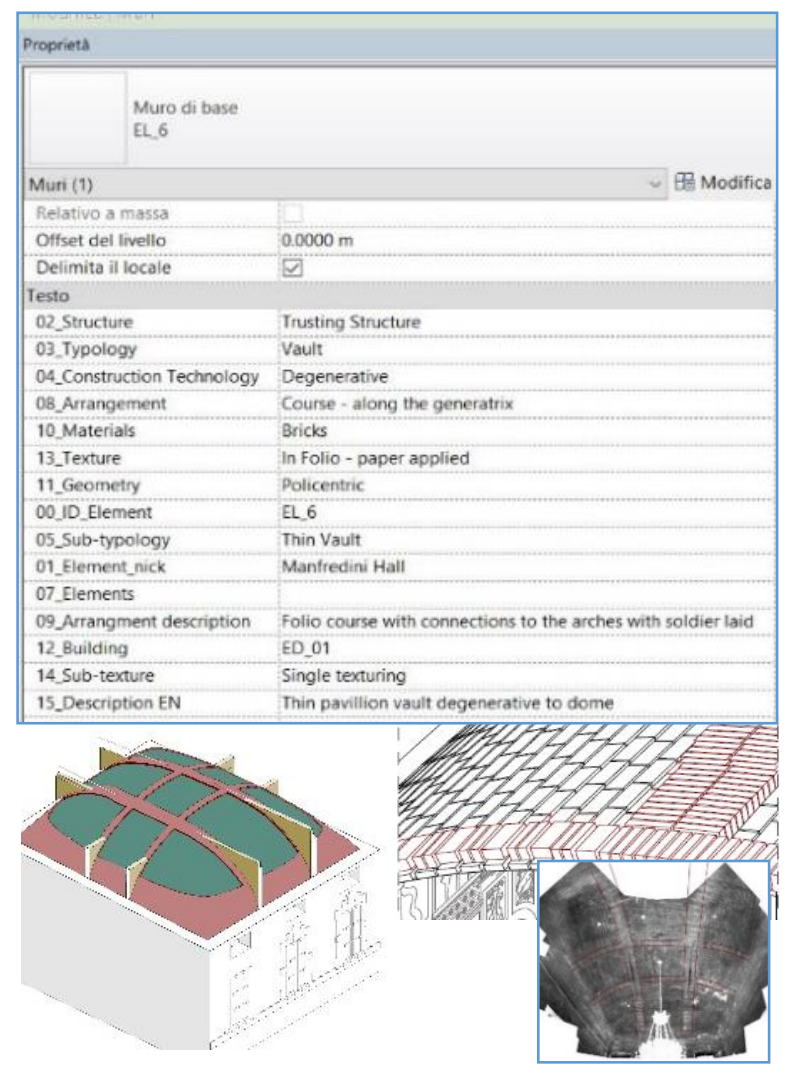

Vault and Dome Construction Typology

Arch and Vault (mixed)

Barrel Vault

Cloister to Dome (centre)

Cloister to Trompe (corners)

Cloister Vault

Cloister-Pavillion Vault

Dome

False Dome

False Vault

'Frenelli'

Groined Vault

Lintel (Filler Tiles)

Lowered brick tile vaults and iron girders

Lunette

Others

Pavillion Vault on circular plan

Pendentive Dome

Planterian Vault

Figure 6 . The vault vocabulary derived from the HBIM of palace (the Magio Grasselli Palace in Cremona):

the bottom up process will allow to compare different HBIM nodes within the Hub platform. 


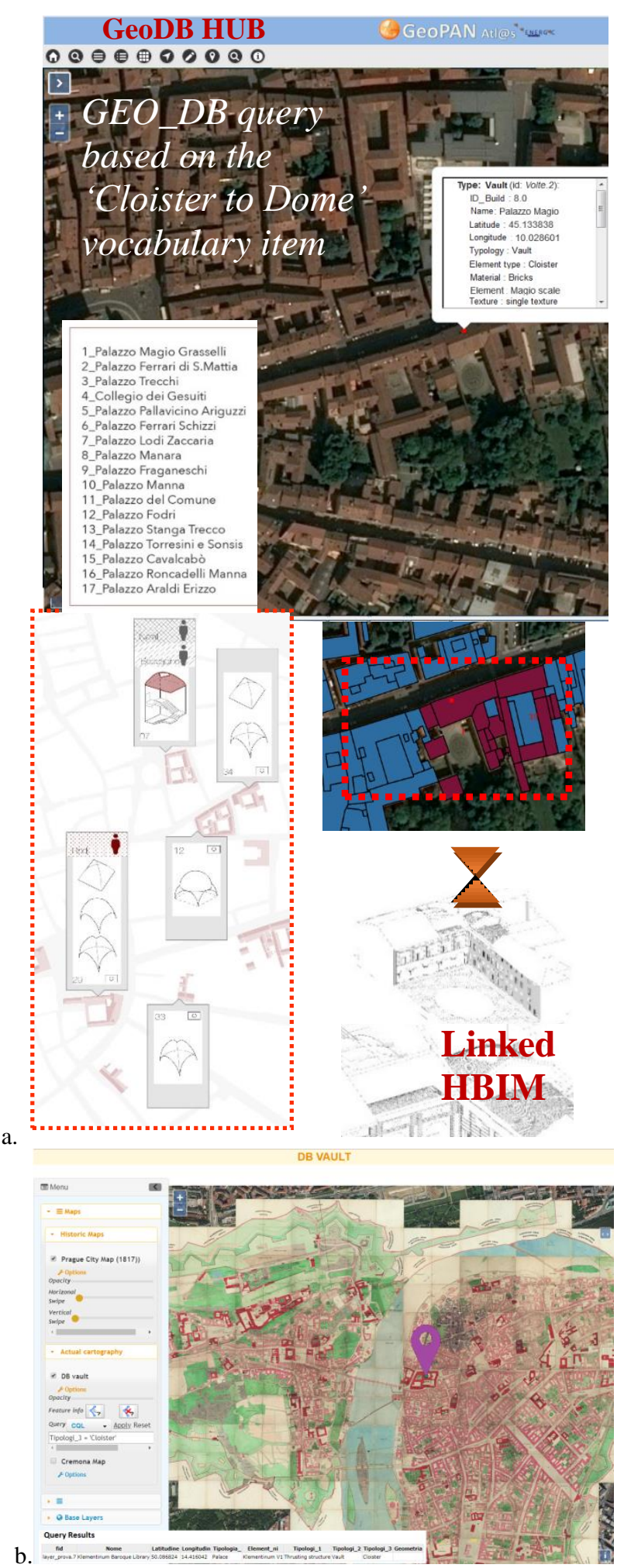

Figure 7 .The GeoPAN APP (GeoDB Hub): (a) the vault inventory of the Cremona Palaces entered in the Data Model and the vault DB queried for a specific vocabulary item (i.e. the

'Cloister to Dome' search typology): the returned ID_08,

Palazzo Magio, Cremona (Italy), with the linked 3DHBIM model, and its DB contents on the vaulted systems; and (b) a similar query in for the area of Prague connecting the historic map of the city and the building vaults surveyed and classified.

\subsection{Libraries of objects, boosting vocabularies and semantics}

The idea is to have an English/Italian validated vocabulary that can be integrated in the time being by multi-language translation. A sort of a common switch among the DB, the HBIMs and the GEODB platform where all these data can be searched by mean of the metadata and contents, allowing to the different researchers to update it with the different experiences, to add new terms, and to the professionals to enrich their work. It is obvious that such approach is scalable, thus it could be applied to many other architectural systems as the masonry textures/materials/construction techniques (on course of definition, as in the case of the Basilica di Collemaggio, Brumana et al., 2018c), or slab/ceiling covering across the world, ancient heating and cooling implants, and many others on course experiences in this direction.

The HBIM is a natural collector of all the materials, characteristics, dating, description of the arrangements, of the stratigraphic units encountered in the surveying analysis performed to prepare the Preservation Plan. All the information managed within the HBIM (Brumana et al., 2018c) can feed vocabularies of materials, together with the finishing techniques. Within the HBIM of the Basilica di Collemaggio it has been created a repository of the materials. The different stone finishing of the façade have been highlighted. The external DB can be extracted and related to other repository of stone finishing allowing historians and professionals to compare similar finishing that characterized different art-facts across the centuries. As in the case of the stone finishing of the façade of the Basilica di Collemaggio (Figure 8), or of the Wailing Wall in Jerusalem or the Nicosia's Patriarchate external (Figure 9).
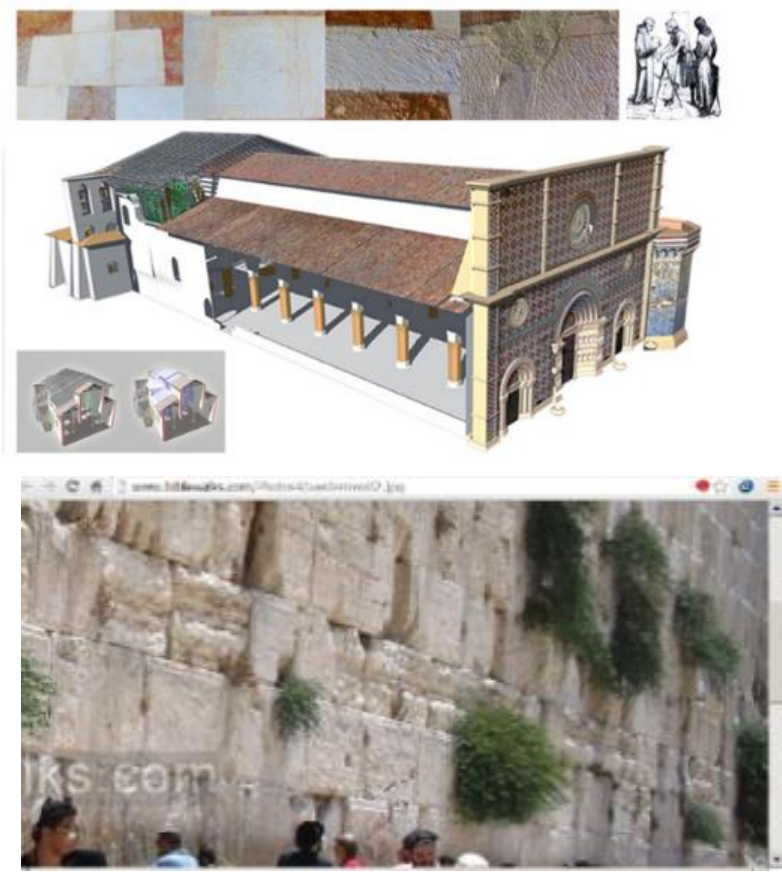

Figure 8. Repositories of materials, construction techniques and masonry arrangements coming from the HBIMs can be connected to other data available on material finishing. Apparently different surface finishing in the Wailing Wall in Jerusalem and in the façade of the Basilica di Collemaggio can be rediscovered by the semantic hub and accessible by citizens through eXtended Reality on common devices and smartphones. 
Holistic HBIMs HUB will require to boost the automatic extraction of HBIM properties, the architecture of open vocabularies coming from the properties related to the object models within the HBIM.

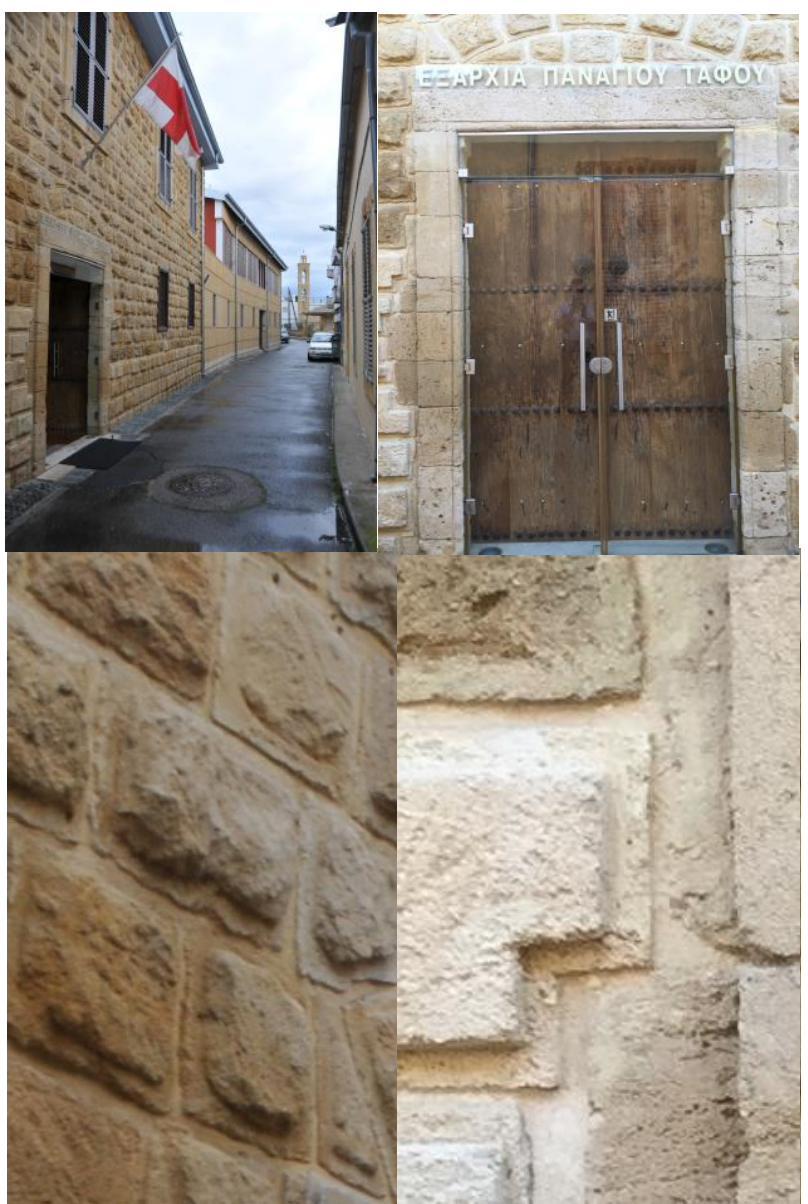

Figure 9. Repositories of materials and masonry arrangements: the Nicosia's Patriarchate external wall

From HBIM to open vocabularies, from sparse data available in non-structured architecture to open vocabularies, in order to match structured and non-structured data.

An Holistic HBIM workflow scheme from the data acquisition to the semantic based GEODB where to connect all the HBIM nodes is illustrated in Figure 10.

This will result in the development of: a) updatable open data libraries of group of elements (so called classes), object components, materials and construction techniques, masonries, covering systems (trusses, domes and vaulted system across the centuries), deriving materials repositories of the local areas through the case studies; b) 3D models enriched by the construction techniques adopted in different territories will allow - for example - the gathering of documentation and the comparison of stone finishing, ancient habits, tangible and intangible values of skilled handicraft specialists across time throughout the regions of the East Mediterranean, Middle East, Balkan creating a system for leveraging also in other widening countries; c) capacity building to manage HHBIM with intangible $\mathrm{CH}$ items, including oral traditions of construction techniques and other media such as the integration of video, dance, music and other source data, once connected to the DBs related to the HBIM.

The enrichment of metadata for HHBIM purposes will need to be boosted in order to better perform semantic queries.

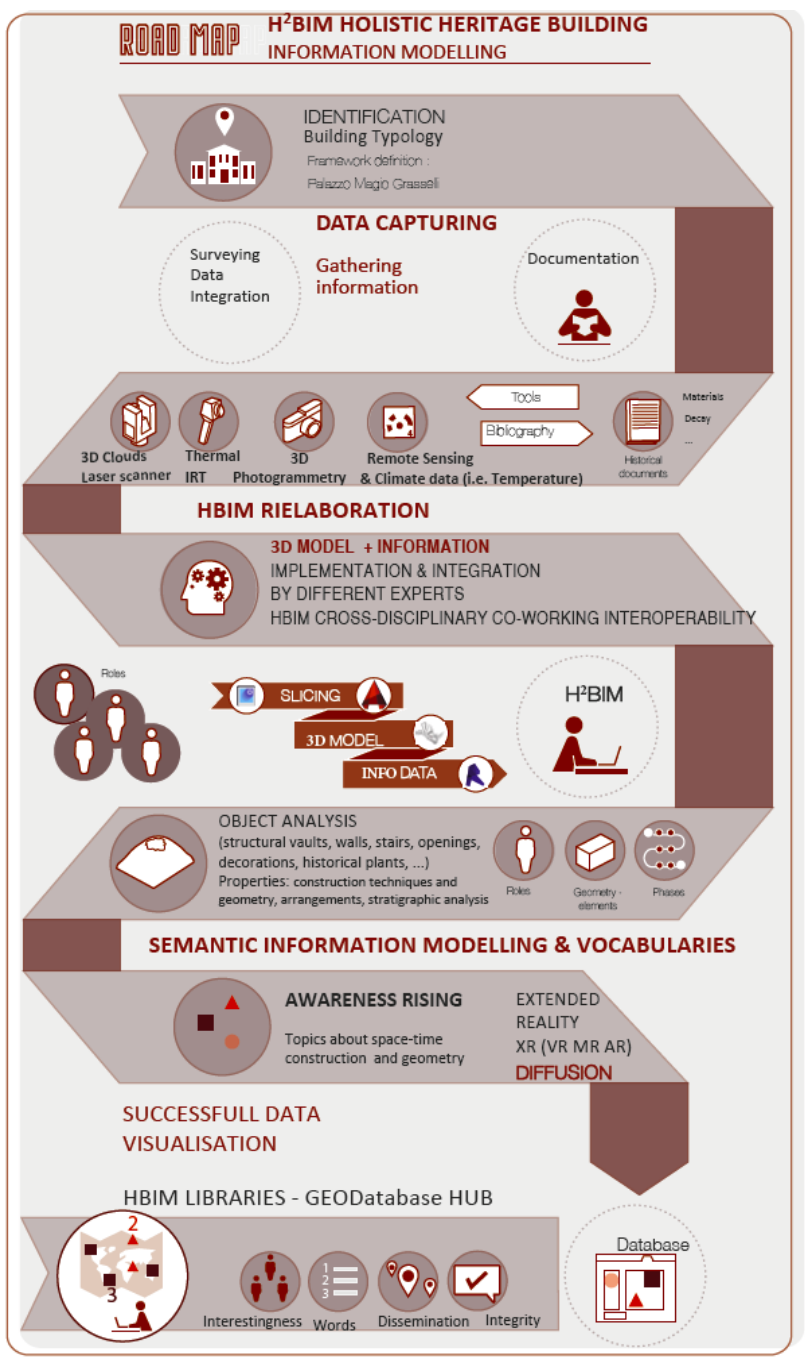

Figure 10. Holistic HBIM HUB workflow scheme

\section{CONCLUSIONS AND REMARKS}

Holistic HBIM vision opens unexpected potentials in the cross correlation among the different HBIM nodes. It requires to empower semantics and ontologies based on vocabularies that can be spread up in a bottom up process from the HBIM nodes. Such richness, once interconnected through modern virtual hub, can be accessed from space-temporal queries, semantic searches; and in future it can be harvested within Europeana networks in order to enhance the portability of the information gained and to share them with other case studies within a spacetemporal framework. This will allow the comparison of different construction techniques, as in the case of vaulted system, or of different masonry arrangements, the use of different materials, history of material finishing and skilled workers across space and time in a Pan-European dimension. The next year will be addressed to implement an open updatable crowdsourced GEODB with linked 3D models and HBIM finalizing it to the construction of repositories making them updatable by different actors (i.e. experts, historians, architects, archaeologists, linguists, surveyors). To do that IPR roles, code implementation, requirements for the different linked 3D formats are few issues to be faced. 


\section{ACKNOWLEDGEMENTS}

The research leading to the results of this paper is partially funded under the ICT Policy Support Programme (ICT PSP) as part of the Competitiveness and Innovation Framework Programme by the European Community (CIP) GA n620400, and by GAMHer project: Geomatics Data Acquisition and Management for Landscape and Built Heritage in a European Perspective, PRIN, Progetti di Ricerca di Rilevante Interesse Nazionale - Bando 2015, Prot. 2015HJLS7E. (Sc. Res. POLIMI Unit R. Brumana). ENI-Service Contract 'Surveying to HBIM of the Basilica di Collemaggio', Brumana R. S. Della Torre.

\section{REFERENCES}

Banfi, F., 2017. BIM orientation: grades of generation and information for different type of analysis and management process. In: The International Archives of the Photogrammetry, Remote Sensing and Spatial Information Sciences, 42(2/W5), pp. 57-64.

Brumana, R., Condoleo, P., Grimoldi, A., Banfi, F., Landi, A.G., Previtali, M., 2018a. HR LOD based HBIM to detect influences on geometry and shape by stereotomic construction techniques of brick vaults. In: Applied Geomatics 10, pp. 529543. DOI 10.1007/s12518-018-0209-3, Special Issue GEORES2017. Geomatics and Restoration: Conservation of Cultural Heritage in the Digital Era ,Springer.

Brumana R., Condoleo P., Grimoldi A., Landi A.G, Attico d., T., Banfi F. and Previtali M., 2018b. HBIM feeding OpenAccess vault inventory through GeoDB HUB, 11196 LNCS, Eds. Fink E., Brumana R.,Wallace M.,Doulamis A.,Patias P.,Ioannides M.,Martins J., Springer Verlag, 10.1007/978-3-030-01762-0_3, pp. 27-38.

Brumana, R., Della Torre, S., Previtali, M., Barazzetti, L., Cantini, L., Oreni, D., Banfi, F., 2018c. Generative HBIM modelling to embody complexity (LOD, LOG, LOA, LOI): surveying, preservation, site intervention - the Basilica di Collemaggio (L'Aquila). In: Applied Geomatics, 10(4), 545567.

Cuca, B., 2017. The contribution of earth observation technologies to monitoring strategies of cultural landscapes and sites, Int. Arch. Photogramm. Remote Sens. Spatial Inf. Sci., XLII-2/W5, 135-140, https://doi.org/10.5194/isprs-archivesXLII-2-W5-135-2017, 2017

Della Torre, S., Mannoni, T., Pracchi, V., 1997. Magistri d'Europa. Como: Nodo Libri.

Della Torre, S., 2015. Shaping tools for Built Heritage Conservation: from architectural design to program and management. Learning from Distretti culturali. Van Balen, K. et al., Community Involvement in Heritage (Reflections on Cultural Heritage Theories and Practices) pp. 93-102.

Della Torre, S., (2016). Perspectives on Historic BIM Developments in Italy, AECbytes, 82 (http://www.aecbytes.com/viewpoint/2016/issue_82.html).

Della Torre, S., (2017). Un bilancio del progetto BHIMM, in S. Della Torre, ed.,. Built Heritage Information Modelling Managament / Modellazione e gestione e delle informazioni per il patrimonio edilizio esistente, Sistema editoriale Ingenio. (https://www.ingenio-web.it/6974-un-bilancio-del-progettobhimm).

De L'Orme, P., 1561. Traites d'architecture : nouvelles inventions pour bien bastir et a' petits fraiz, Premier tome de l'architecture (1567), presentation par J.M. Perouse de Montclos. - Leonce Laget, Paris 1988.

Diderot, D., Le Rond D'Alambert, J.B., 1753. Encyclopédie ou dictionnaire raisonné des sciences, des arts et des meétiers, Le Breton, Parigi.

Holzer, S.M., (2013). Statische Beurteilung historischer Tragwerke vol. I Mauerwerkskonstruktionen. Enrst \& Sohn, Berlin.

Kuo, C. L., Cheng, Y. M., Lu, Y. C., Lin, Y. C., Yang, W. B., Yen, Y. N., 2018. A Framework for Semantic Interoperability in 3D Tangible Cultural Heritage in Taiwan. In EuroMediterranean Conference (pp. 21-29). Springer, Cham.

Jean, G., (1998). I lavori di Faustino Rodi nel Palazzo comunale di Cremona. In: Bollettino storico cremonese. pp.126-138.

Landi, A., (2011). Riforme edilizie in una dimora aristocratica cremonese: palazzo Magio-Grasselli. In: Landi A. (Ed.), Patrizi, notabili, costruzione della città. Palazzo Magio-Grasselli a Cremona tra civitas e urbs. U. Allemandi, Torino, pp. 33-116.

Mazzetti, P., Latre, M. Á., Ernst, J., Brumana, R., Brauman, S., Nativi, S., 2015. Virtual hubs for facilitating access to open data. In EGU General Assembly Conference (Vol. 17)

Napolitano, R. K., Douglas, I. P., Garlock, M. E., and Glisic, B. (2017) VIRTUAL TOUR ENVIRONMENT OF CUBA'S NATIONAL SCHOOL OF ART, Int. Arch. Photogramm. Remote Sens. Spatial Inf. Sci., XLII-2/W5, 547-551, https://doi.org/10.5194/isprs-archives-XLII-2-W5-547-2017, 2017.

Oreni, D., Brumana, R., Georgopoulos, A., Cuca B., (2013). HBIM for conservation and management of built heritage: towards a library of vaults and wooden beam floors. In: Grussenmeyer, P. (Ed.), ISPRS Annals of Photogrammetry, Remote Sensing and Spatial Information Sciences, vol. II-5/W1. Copernicus Publications. pp. 215-221.

Pérouse de Monclos, J.M. (Ed.), (1972). Architecture, vocabulaire, Ministère de la culture et de la communication, Inventaire général des monuments et des richesses artistiques de la France. Imp. Nationale, Paris.

Piccoli, E., (1999). Volte composte nell'architettura piemontese del Settecento: le volte planteriane. In: PALLADIO, VII(23), pp.87-100.

Previtali, M., 2017. Geopan atl@s: A brokering based gateway to georeferenced historical maps for risk analysis. International archives of the photogrammetry, remote sensing and spatial information sciences, 42(2W5), 583-589.

Rondelet, J.B., 1802. Traité theorique et pratique de l'art de batir, Paris, 1802-1807, trad. it. a cura di B. Soresina, Trattato teorico e pratico dell'arte di edificare, Fratelli Negretti, Mantova, 1832-1841, vol. II e III.

Strategic Research Agenda, http://www.jpiculturalheritage.eu/wp-content/uploads/SRA-2014-06.pdf

Getty Vocabulary, On line Web form, http://vocabcontrib.getty.edu/web-form/login.aspx

UNI 11337:2017,

http://www.uni.com/index.php?option=com_rseventspro\&layou $\mathrm{t}=$ show\&id=1264\%3Auni-11337-2017-gestione-digitale-diprocessi-informativi-delle-costruzioni-bim (UNI 11337-3-2017 under discussion for LOG and LOI definition). 